P0-0359 HOW TO SELECT THE SWEAT TEST CANDIDATE. 10 YEARS OF EXPERIENCE IN SCREENING FOR CYSTIC FIBROSIS IN CHILDREN

${ }^{1} \mathrm{M}$ Neamtu, ${ }^{1} \mathrm{~L}$ Dobrota, ${ }^{1} \mathrm{~B}$ Neamtu, ${ }^{1} \mathrm{C}$ Berghea Neamtu, ${ }^{1} \mathrm{C}$ Cazan, ${ }^{2} \mathrm{E}$ Rob, ${ }^{2} \mathrm{~A}$ Pavel, ${ }^{2} \mathrm{~F}$ Diac. ${ }^{1}$ Pediatric Clinic, Pediatric Clinic Hospital "Lucian Blaga" University of Sibiu, Sibiu, Romania; ${ }^{2}$ Pediatric Clinic, Pediatric Clinic Hospital, Sibiu, Romania

\subsection{6/archdischild-2014-307384.1007}

Background Sweat test (ST) remains gold standard in cystic fibrosis (CF) diagnosis. Alarm symptoms are age-related.

Aims Retrospective review of cases subjected to ST.

Methods Patients were selected by paediatricians, neonatologists, surgeons, based on suggestive symptoms, personal $(\mathrm{PH})$ and familial history $(\mathrm{FH})$. Inclusion criteria: for $0-1$ month age group, patients with $\mathrm{PH}$ of atelectasis, meconium ileus, intussusception; 1-12 months, recurrent wheezing (RW), failure to thrive (FTT); 1-5 years, previous group symptoms, plus chronic cough/diarrhoea; $>5$ years, $1-5$ years symptoms, plus recurrent pancreatitis/ sinusitis. For all age, patients with $\mathrm{PH}$ of salty taste of sweat (STS), salt wasting syndrome, heat shock (HS), and FH of CF, azoospermia. ST was performed with Nanoduct system. Values $<60 \mathrm{mmol} / \mathrm{L}$ (equivalent $\mathrm{NaCl}$ ) were considered normal, between 60-80 equivocal, $>80$ positive. Normal values patients were eventually retested, those with equivocal at least once, those with positive mandatory twice.

Results Were performed 406 ST (344 patients): at 0-1 month 11 tests (45,4\% peritonitis), at 1-12 months $175(65,5 \%$ RW), at 1-5 years $108(25,9 \%$ FTT $)$, at $>5$ years $50(62,5 \%$ repeated pneumonia-RP). 4 tests equivocal, 5 false positive, 6 positive $(5$ infants: $1 \mathrm{RW}, 1 \mathrm{HS}, 2$ atelectasis, 1 STS; 1 male 4 years old $\mathrm{RP})$. Relating to age, only 1 positive from $141 \mathrm{RW}$ infants ( $\mathrm{p}$ $0,03)$ and 1 from $15 \mathrm{RP}$ children; 2 positive from 6 atelectasis infants ( $p$ 0,0001), 1 from 2 HS and 1 from 2 STS infants ( $p$ 0,0002). Neither pancreatitis, FTT or positive FH.

Conclusions Great attention on infants with other symptoms than classical ones: higher statistical significance for STS, HS, atelectasis.

\section{PO-0360 BONE MINERAL DENSITY IN EGYPTIAN CHILDREN WITH FAMILIAL MEDITERRANEAN FEVER}

${ }^{1} \mathrm{~S}$ El-Masry, ${ }^{2} \mathrm{~S}$ Salah, ${ }^{1}$ RA El-Banna. 'Biological Anthropology, National Research Centre, Giza, Egypt; ${ }^{2}$ Rheumatology Department, Cairo University, Giza, Egypt

\subsection{6/archdischild-2014-307384.1008}

Background Familial Mediterranean fever (FMF) has episodic or subclinical inflammation that may lead to a decrease in bone mineral density (BMD).

Objective To assess BMD in Egyptian children with FMF on genetic basis.

Subjects and methods A cross sectional study included 45 FMF patients and 25 control children of both sexes, with age range between 3-16 years old. The patients were reclassified into 2 groups: Group I (A) 23 cases used colchicines for 1 month or less, and Group I (B) 22 cases used colchicines for more than 6 months. For both patients and control, MEFV mutations were defined using molecular genetics technique and BMD was measured by DXA at 2 sites: proximal femur and the lumber spines. Results four frequent gene mutation where found in the patient group: E148Q (35.6\%), V726A (33.3\%), M680I (28.9.0\%) and M694V (2.2\%). There were also 4 heterozygous gene mutations in $40 \%$ of control children. Patients received Colchicines treatment for less than 1 month had highly significant lower values of BMD at femur and lumber spines than control children ( $\mathrm{p}$ $<0.007, \mathrm{p}<0.001)$. Patients received Colchicines treatment for more than 6 months had improved values of BMD at femur compared to control, but there were still significant differences between them at lumbar spine $(p>0.036)$. There are insignificant effect of type of gene mutation on BMD and the risk of osteopenia among the patients.

Conclusion FMF had significant effect on BMD. However; regular use of colchicines treatment improves this effect mainly at femur.

\section{PO-0361 FOODBORNE ILLNESSES IN MOROCCAN CHILDREN: RESULTS OF A NATIONWIDE STUDY}

${ }^{1} \mathrm{~F}$ Hadrya, ${ }^{1} \mathrm{H}$ Hami, ${ }^{2} \mathrm{~S}$ Benlarabi, ${ }^{2} \mathrm{R}$ Soulaymani-Bencheikh, ${ }^{1} \mathrm{~A}$ Mokhtari, ${ }^{1} \mathrm{~A}$ Soulaymani. ${ }^{1}$ Laboratory of Genetics and Biometry, Faculty of Science Ibn Tofail University, Kenitra, Morocco; ${ }^{2}$ Moroccan Poison Control Center, Rabat, Morocco

\subsection{6/archdischild-2014-307384.1009}

Background and aims Foodborne illnesses are a serious public health issue, especially among children in developing countries. The aim of this study is to determine the magnitude of foodborne diseases and associated risk factors among children in Morocco.

Methods We conducted a retrospective study of foodborne diseases in children under the age of 6 years, notified between 1992 and 2008, to the Moroccan Poison Control Centre.

Results There were 2589 cases of food poisoning and 12 deaths reported in children during the study period. The foods most often involved were dairy products, fish and fishery products. The median delay in presentation to hospital was $9 \mathrm{~h}$. The majority of children had gastrointestinal symptoms, associated or not with respiratory, cardiovascular and neurological symptoms. On admission to hospital, the majority of patients received symptomatic treatment. According to the results, region of origin, types of symptoms and the delay before treatment were significant risk factors influencing patients' health status. The risk of death due to poisoning was significantly higher among patients presenting with arrhythmias, apnea, hypothermia, hypotonia, bradycardia and coma.

Conclusions Foodborne diseases are a significant public health problem in both developed and developing countries. The effective treatment remains prevention focused on public awareness about the dangers of food poisoning, especially for young children.

\section{PO-0362 THE SILVER-RUSSELL SYNDROME: REPORT OF 2 CASES}

S Hammami, H Besbès, M Charfi, CH Ben Meriem, S Hadded, MN Guédiche. Pediatric, Fattouma Bourguiba Hospital, Monastir, Tunisia

\subsection{6/archdischild-2014-307384.1010}

Background The Silver-Russell syndrome is rare pattern of malformations which associated growth retardation generally starting in antenatal period, a characteristic facial feature and limb asymmetry. We report two new cases illustrating this syndrome. Observation 1 A female infant was admitted in paediatric department at the age of 4 months. The neonatal period was unremarkable; the infant had no intrauterine growth retardation (birth weight and height ranging between the 25th and 50th percentile). The infant's head circumference was large contrast with 